\title{
Treat the Patient, Not the Pain: Using a Multidimensional Assessment Tool to Facilitate Patient-Centered Chronic Pain Care
}

\author{
Dale J. Langford, $P h D^{7}$, David J. Tauben, MD, FACP' , John A. Sturgeon, PhD ${ }^{7}$, Daniel S. Godfrey ${ }^{7}$, \\ Mark D. Sullivan, MD, $P h D^{2}$, and Ardith Z. Doorenbos, RN, PhD, FAAN ${ }^{3}$
}

'Department of Anesthesiology and Pain Medicine, University of Washington, Seattle, WA, USA; ${ }^{2}$ Department of Psychiatry and Behavioral Sciences, Seattle, WA, USA; ${ }^{3}$ Department of Biobehavioral Nursing and Health Informatics, Seattle, WA, USA.

KEY WORDS: chronic pain; pain management; assessment; patientcentered care.

$\mathrm{J}$ Gen Intern Med 33(8):1235-8

DOI: $10.1007 / \mathrm{s} 11606-018-4456-0$

(c) Society of General Internal Medicine 2018

\section{THE NEED FOR MULTIDIMENSIONAL CHRONIC PAIN ASSESSMENT}

Chronic pain is common, complex, costly, and distressing to patients, families, and clinicians. Despite multiple national initiatives, ${ }^{1}, 2$ improvements in chronic pain management have been limited. In fact, an estimated $40-60 \%$ of patients with chronic pain have inadequate pain management. ${ }^{3}$ This lack of progress may partly be due to the multidimensionality of chronic pain, which is not routinely incorporated into its assessment and management. A patient-centered approach - that accounts for patient-specific goals and patient-reported outcomes and can be implemented in a congested, time-limited primary care clinic setting - is needed to achieve the primary goals of chronic pain management, including reduction of pain impact and improvement of function and quality of life. ${ }^{3,4}$

\section{A QUESTION UNASKED IS AN ANSWER UNLEARNED: USE OF A PATIENT-REPORTED OUTCOMES TOOL TO PROVIDE MULTI-MODAL CHRONIC PAIN CARE}

To facilitate individually tailored, comprehensive chronic pain care and patient engagement in pain management, clinicians and informaticists at the University of Washington (UW) Center for Pain Relief developed an online patient-reported outcome measurement tool, called PainTracker ${ }^{\mathrm{TM}}$. New patients seeking care at UW's Center for Pain Relief receive unique login information to complete the online PainTracker assessment prior to their clinic appointment, and data are accessed by clinic intake staff through the PainTracker provider portal. As described in Table 1, intake assessments include questions about treatment history, treatment goals and expectations, as well as pain (e.g., pain intensity, interference, pain-related disability, problems with pain medications) and non-pain (e.g., anxiety, depression, health-related quality of life) domain questionnaires. In addition, a body diagram and supplemental questionnaires aid in the diagnosis of specific pain conditions (e.g., radiculopathy versus widespread pain that may indicate fibromyalgia). Providers are alerted when patients' risk or symptom severity scores exceed established threshold values (see Fig. 1), and so support clinical decisions addressing key patient psychosocial problem areas (e.g., referral to behavioral health, sleep specialists).

Prior to each follow-up appointment, patients complete a subset of core outcome questions (see Table 1). PainTracker displays longitudinal data graphically for providers and patients to quickly visualize areas of improvement or continued difficulty and tailor treatment accordingly. This systematic multidimensional assessment allows for the delivery of dynamic, individualized pain management and accurate evaluation of response to treatment(s). Review of PainTracker graphs with patients allows providers to demonstrate that improvement in sleep, function, and mood often occurs before improvement in pain (see Fig. 1). Identification of treatment goals and expectations is a critical component of PainTracker that engages patients as active participants in their care, facilitates patient-provider communication, promotes individually tailored benchmarks for improvement, and ensures realistic treatment expectations.

An evaluation of aggregate PainTracker data illustrates the necessity for multidimensional pain assessment. A substantial proportion of more than 4000 adult patients exceeded clinically meaningful threshold values for depression $(57.4 \%)$, anxiety $(33.3 \%)$, and post-traumatic stress disorder (27.7\%). Most patients were severely disabled or worse $(64.7 \%)$ and many

Published online May 1, 2018 
Table 1 Constructs and Outcomes Measured by PainTracker ${ }^{\mathrm{TM}}$ at Intake and Follow-up

\begin{tabular}{|c|c|c|}
\hline Construct/outcome & Measure & $\begin{array}{l}\text { Alert triggering score } \\
\text { (if applicable) }\end{array}$ \\
\hline \multicolumn{3}{|l|}{ Intake only: treatment history, expectations, and risk assessment } \\
\hline Treatment history & $\begin{array}{l}\text { No. of visits with provider types; } \\
\text { efficacy of past treatments }\end{array}$ & \\
\hline Treatment expectations & Top 3, ranked & \\
\hline Risk for opioid misuse & ORT & $\geq 8$ \\
\hline Post-traumatic stress disorder screen & PC-PTSD & $\geq 3$ \\
\hline Prescription opioid difficulties & PODS & \\
\hline Alcohol use disorder screen & AUDIT-C & $\begin{array}{l}\geq 3 \text { (women) } \\
>4 \text { (men) }\end{array}$ \\
\hline Fibromyalgia screen & $\begin{array}{l}\text { FS: body map (no. of pain sites } \\
\text { based on WPI) + SSS }\end{array}$ & $\geq 13$ \\
\hline \multicolumn{3}{|c|}{ Intake and follow-up: pain, pain interference, disability, mood, QOL medication problems, and treatments } \\
\hline Treatment goals & Top 3, ranked & \\
\hline Pain intensity and interference with enjoyment of life and general activity & PEG & \\
\hline Pain interference with sleep initiation and maintenance & NRS $(0-10)$ & \\
\hline Difficulty with patient-specified activity & NRS $(0-10)$ & \\
\hline Pain-related disability & ODI & $\geq 41 \%$ (severe) \\
\hline Pain locations (worst and other) & Body diagram & \\
\hline Depression & PHQ-9 & $\geq 10$ \\
\hline Anxiety & GAD-7 & $\geq 10$ \\
\hline Panic attack & Yes/no & \\
\hline Global health-related QOL & PROMIS Global & \\
\hline Side effects of pain medications & Yes/no & \\
\hline Risk for obstructive sleep apnea & STOP & $\geq 2$ \\
\hline Days when more pain medication was needed & None, $1-2,3-45$ or more & \\
\hline Procedures/treatments & Types and start dates & \\
\hline Treatment satisfaction & NRS $(0-10)$ & \\
\hline
\end{tabular}

References and more detailed description of most instruments described elsewhere 5

Abbreviations: AUDIT-C Alcohol Use Disorders Identification Test; FS fibromyalgia symptoms; GAD-7 Generalized Anxiety Disorder 7-item scale; NRS Numeric Rating Scale; ODI Oswestry Disability Index; ORT Opioid Risk Tool; PC-PTSD Primary Care-Post-traumatic Stress Disorder screener; PEG Pain intensity and interference with Enjoyment of life and General activity; PHQ-9 Patient Health Questionnaire (depressive symptoms); PODS Prescribed Opioids Difficulty Scale; PROMIS Global Patient-Reported Outcomes Measurement Information System-Global Quality of life; SSS Symptom Severity Score; STOP Snoring, Tiredness, Observation of stopped breathing; high blood Pressure; WPI Widespread Pain Index

were identified as moderate-high risk for opioid misuse (40.1\%) and high risk for obstructive sleep apnea (56.7\%) (unpublished data). Knowledge of these problem areas can save patients and providers valuable time and frustration from disappointing treatment failures.

\section{ROLE OF PRIMARY CARE}

Primary care physicians play an integral role in the successful coordination of chronic pain care and the implementation of standardized, multidimensional assessment is necessary for the provision of effective multi-modal patient-centered care. Such measurement is essential for establishing clinical practice guidelines for coordinated inter-specialty care of patients with chronic pain, such as measurement-based "step care." Importantly, a sample of primary care providers $(N=30)$ found an early version of PainTracker easy to use (70\%) and believed it helped patients to participate in their pain management (77\%), ${ }^{6}$ providing evidence of the acceptability, feasibility, and utility of incorporating measurement-based chronic pain care into the primary care setting. While PainTracker is not currently available outside the University of Washington system, the instruments included are freely available and can be adopted for use in the primary care setting. A paper version can suffice as an early adoption strategy.

The systematic evaluation of patient-reported outcomes spanning pain and non-pain domains is necessary for capturing the multidimensionality of the pain experience, useful for guiding treatment decisions, and enhances patient engagement in their own pain care. 


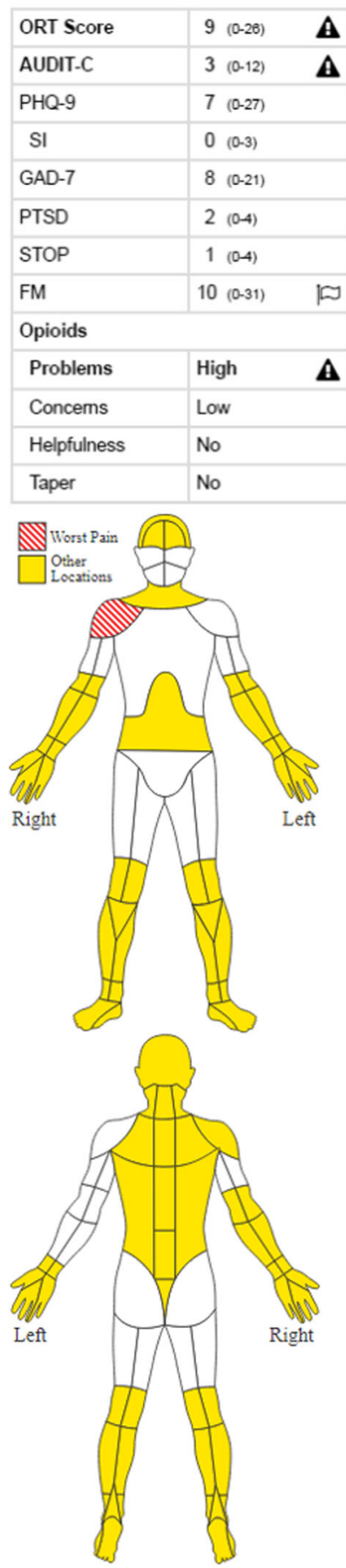

Printed: 1/8/2018

$\mathbf{A}$

Last Completed Session: 1/8/2018 9:59am

\section{.}

\begin{tabular}{|c|c|c|c|c|c|}
\hline \multicolumn{3}{|c|}{ Patient-reported Recent Treatments } & \multicolumn{3}{|c|}{ Patient-reported Treatment Goals and Expectations } \\
\hline Type & Last 3 Dates & Total & Rank & Goals (1/8/18) & Expectations (1/2/18) \\
\hline ....... Injection & $12 / 20 / 17,12 / 6 / 17$ & 2 & $1 \mathrm{st}$ & Help w/ important activities & Medications for pain \\
\hline ..-.. Started Phys. Therapy & $1 / 3 / 18$ & 1 & 2nd & Help coping w/ pain & Physical Therapy \\
\hline — Started Psych. Therapy & Not reported & 0 & 3rd & A reduction in pain & Counseling \\
\hline
\end{tabular}
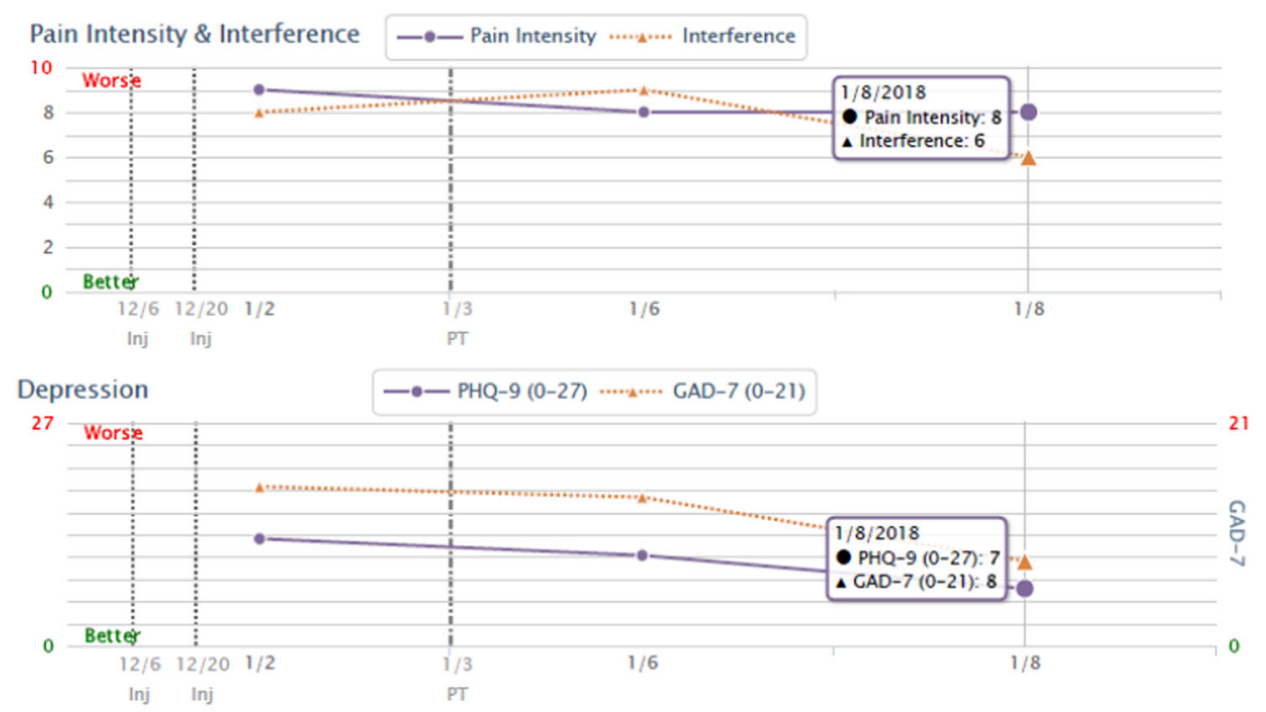

Sleep Initiation \& Maintenance $\longrightarrow$ - Sleep Initiation …...... Sleep Maintenance

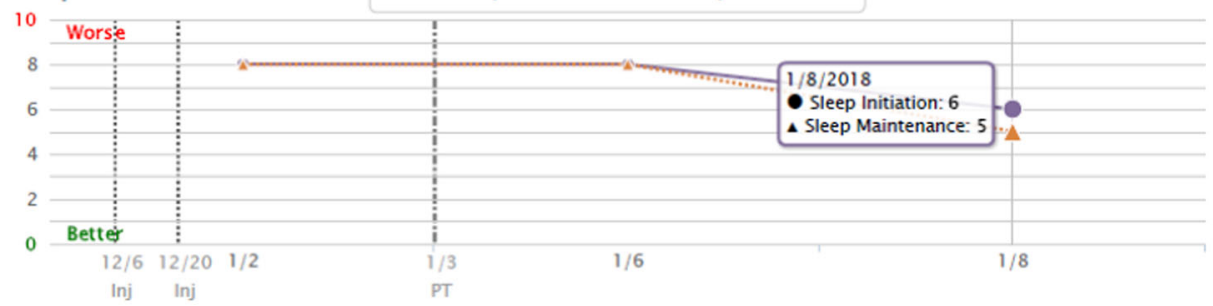

ODI \& Important Activity Difficulty —— ODI (0-100) …...... Important Activity Difficulty

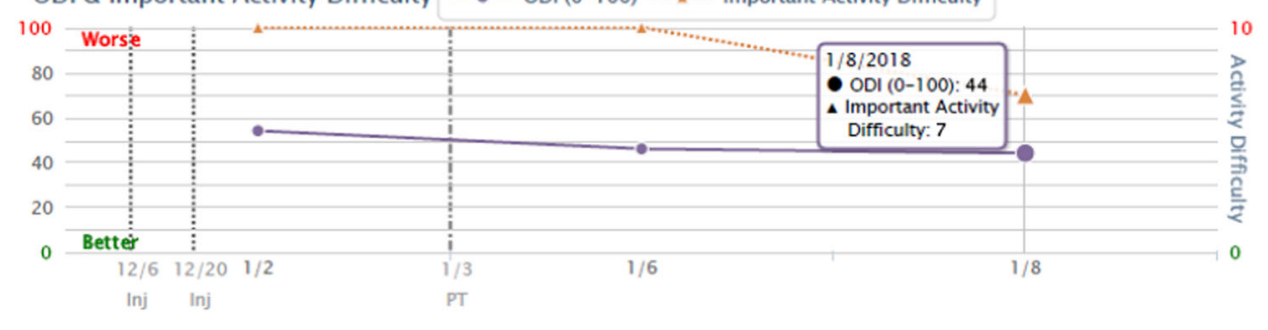

Most Bothersome Side Effect (From most recent assessment)

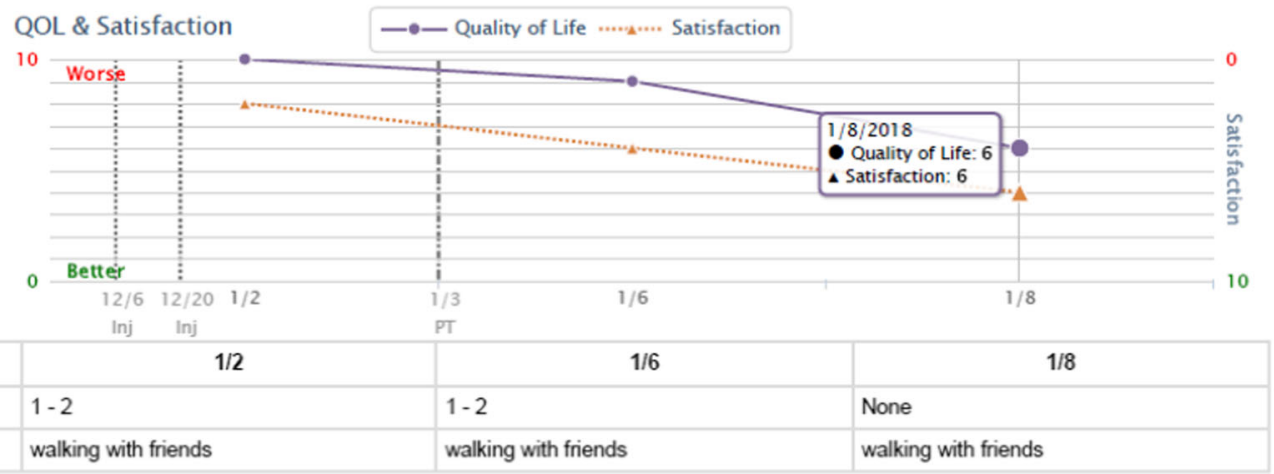

Trouble concentrating

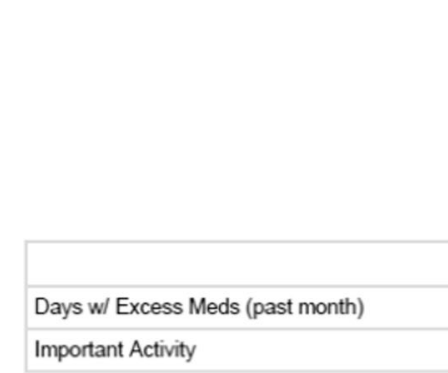

Fig. 1 Primary section of the PainTracker ${ }^{\mathrm{TM}}$ report from fictitious patient with chronic pain. Copyrighted by the University of Washington. 
Acknowledgements: Contributors: University of Washington Clinical Informatics Research Group

Corresponding Author: Dale J. Langford, PhD; Department of Anesthesiology and Pain Medicine University of Washington, 1959 NE Pacific Street, Seattle, WA, USA (e-mail: dalejwl@uw.edu).

Funding Information This work was supported by the National Institute of Nursing Research of the National Institutes of Health under award number K24 NR015340 (Doorenbos). PainTracker development was previously supported by a University of Washington Center for Commercialization project award (Sullivan) and a Pfizer Medical Education grant (Sullivan).

\section{Compliance with Ethical Standards:}

Conflict of Interest: None of the authors have any conflicts of interest to disclose.

\section{REFERENCES}

1. Relieving Pain in America: A Blueprint for Transforming Prevention, Care, Education, and Research. Washington, DC. The National Academies Collection: Reports funded by National Institutes of Health; 2011.

2. Department of Health and Human Services: National Pain Strategy: A Comprehensive Population Health Strategy for Pain. Available at: https:// iprcc.nih.gov/sites/default/files/HHSNational_Pain_Strategy_508C.pdf Accessed March, 2018.

3. Mills, S., Torrance, N. \& Smith, B. H. Identification and Management of Chronic Pain in Primary Care: a Review. Curr Psychiatry Rep 2016; 18:22.

4. The Interagency Pain Research Coordinating Committee: Federal Pain Research Strategy. Available at: https://iprcc.nih.gov/sites/default/files/ iprcc/FPRS_Research_Recommendations_Final_508C.pdf Accessed March, 2018.

5. Tauben, D. Chronic Pain Management: Measurement-Based Step Care Solutions. IASP: PAIN Clinical Updates. 2012; 20:1-8.

6. Schorn, M. M., Doorenbos, A. Z., Gordon, D. \& Read-Williams, P. Survey of Primary-Care Providers on Perceived Benefits of and Barriers to PainTracker. J Nurse Pract. 2014; 10:781-786. 